\title{
Outcome for newborn babies declined admission to a regional neonatal intensive care unit
}

\author{
D G SIMS, J WYNN, AND M L CHISWICK \\ North-Western Regional Perinatal Centre, Neonatal Medical Unit, St Mary's Hospital, Manchester
}

SUMMARY Between July 1979 and June 1980 the regional neonatal intensive care unit (NICU) at St Mary's Hospital, Manchester, received 170 requests from maternity units for the transfer of ill newborn babies. Most of the babies were suffering from respiratory failure. The initial request was declined in 65 babies because of overcrowding or lack of facilities at the NICU $(n=59)$, or because transfer was not justified on medical grounds $(n=6)$. Forty-two of the 65 babies were compelled to remain in the maternity unit because they could not be accommodated at hospitals with facilities for ventilating newborn babies. The neonatal survival rate of babies with respiratory failure who were transferred to the NICU was $66 \%$ whereas the survival rate of similar babies who were declined transfer was $30 \%$. Our findings support the efficacy of intensive care for ill babies with respiratory failure and suggest that such facilities need to be more widely developed.

A service for the transfer of ill or high-risk neonates to regional neonatal intensive care units (NICU) has been widely developed in the USA as part of perinatal care programmes ${ }^{1}$ and is established in certain regions here. ${ }^{2} 3$ Yet some paediatricians challenge the claim that neonatal intensive care is beneficial..$^{4-6}$ The referral service in the north-western region is mainly directed towards neonates who are critically ill. The demand for this service is increasing and many babies for whom transfer is requested cannot be accommodated. The outlook for babies who were declined admission to a regional NICU has not been reported; yet this is essential information for those contemplating and seeking to justify the development of a regional service.

\section{Patients and methods}

The operation of the regional neonatal intensive care service based at St Mary's Hospital, Manchester, has been described previously. ${ }^{3} 7$ Each time between July 1979 and June 1980 that a request to receive a baby was declined, a record was kept of the baby's name, birthweight, gestational age, referring hospital, indication for the transfer request, and the reasons for not accepting the transfer. If referral was refused because of shortage of nursing or medical staff, overcrowding of patients, or lack of equipment at the regional NICU the decision was always made jointly by the neonatal registrar and senior sister on duty. If it was thought that referral was not indicated on medical grounds the decision was made by the consultant paediatrician or senior registrar on duty. The outcome of such babies was confirmed by discussion with the special care baby unit staff at the referring hospitals several months after the request for transfer had been made.

Definitions. The following definitions were used.

Deteriorating respiratory distress-tachypnoea, thoracic cage retraction, or grunting worsening over the course of $\mathbf{4}$ hours, or accompanied by a progressive fall in arterial oxygen partial pressure, blood $\mathrm{pH}$, or a rise in arterial carbon dioxide partial pressure.

Respiratory distress with superimposed apnoeic attacks-tachypnoea, thoracic cage retraction, or grunting punctuated by episodes of apnoea.

Recurrent apnoeic attacks-repeated episodes of apnoea, without associated respiratory distress.

Ventilatory failure from birth-the persisting need for positive pressure ventilation from birth because of inability to maintain spontaneous breathing.

Impending or actual respiratory failure $(R F)$ - the occurrence of deteriorating respiratory distress or respiratory distress with superimposed apnoeic 
attacks, or apnoeic attacks alone, or ventilatory failure since birth.

\section{Results}

During the study period 170 requests for transfer of ill neonates were received from 17 different maternity units situated between 3 and 120 miles from the regional NICU. One hundred and five babies were immediately accepted but 5 of them died before they could be transferred.

The initial request for transfer was declined in 65 babies for the reasons shown in Table 1. Of the 6 babies declined admission on medical grounds, 3 were moribund and had grossly abnormal neurological behaviour, one was 24 weeks' gestation and weighed only $440 \mathrm{~g}$, one was a healthy preterm baby, and one had diarrhoea and was thought to be an infection risk. Nine of the babies initially declined admission were subsequently transferred to the regional NICU as facilities became available after a delay of 1 to 6 days, 14 were transferred to one of three other hospitals with facilities for ventilating newborn babies, and 42 remained in the maternity unit of birth. If referring hospitals are grouped according to their distances (miles) from the regional NICU $(3-10 ; 11-30 ; 31-120)$, the percentage of requests that were initially declined is similar in each group (27 $(35 \%)$ out of $78 ; 32(41 \%)$ out of 78 ; $6(43 \%)$ out of 14$)$. However, the percentage of requests for transfer that were declined to individual hospitals ranged from 17 to $73 \%$. The indications for the referral request of the 100 babies transferred at once to the regional NICU and the 42 babies who remained in the maternity unit of birth are shown in Table 2. In both groups of babies RF was the most common reason for requesting transfer. Requests for referral on the grounds of prematurity alone were more common in babies who were declined admission and who remained in their maternity unit of birth. None of the 6 babies declined admission on medical grounds is represented among the babies with RF.

Table 3 gives details of the 92 babies with RF who were promptly transferred to the regional

Table 1 Reasons for declining transfer of 65 babies*

\begin{tabular}{lrr}
\hline & $N o$ & $\%$ \\
\hline Overcrowding of patients or shortage & 48 & 74 \\
$\quad$ of equipment & 15 & 23 \\
Shortage of trained nursing staff & 6 & 9 \\
Transfer not justified on medical grounds & 3 & 5 \\
Shortage of medical staff & 3 & 5 \\
Unspecified &
\end{tabular}

*There was more than one reason for some babies.
Table 2 Indications for referral requests in babies promptly transferred to the regional NICU and in those declined transfer who remained in the maternity unit of birth

\begin{tabular}{lccccc}
\hline Indication & \multicolumn{2}{l}{$\begin{array}{l}\text { Transferred } \\
(n=100)\end{array}$} & & \multicolumn{2}{l}{$\begin{array}{l}\text { Declined transfer } \\
(n=42)\end{array}$} \\
\cline { 2 - 3 } \cline { 5 - 6 } \cline { 5 - 6 } & No & $\%$ & & No & $\%$ \\
\hline Respiratory failure & 92 & 92 & & 27 & 64 \\
Prematurity alone & 2 & 2 & & 9 & 21 \\
Other indications & 6 & 6 & & $6^{*}$ & 14 \\
\hline
\end{tabular}

- Includes 5 babies declined admission on medical grounds.

NICU and the 27 with RF who remained in the maternity unit of birth. The mean \pm SD birthweight, gestational age, and the $M: F$ ratio of babies in these two groups were similar. Deteriorating respiratory distress was the most common form of RF in both groups of babies: the occurrence of respiratory distress with superimposed apnoeic attacks was more common in transferred babies compared with those declined transfer but the difference was not significant. The neonatal survival rate in babies with RF who were promptly transferred to the regional NICU $(66 \%)$ was more than double that of similar babies who remained in the maternity unit because the regional NICU could not accommodate them $(30 \%)(\mathrm{P}<0.005)$.

All 9 babies who were later transferred to the regional NICU after initially being declined were suffering from RF and $4(44 \%)$ survived. Eleven of the 14 babies transferred to the other children's hospitals had RF and 5 (46\%) survived.

Table 3 Characteristics and neonatal survival rates of babies with respiratory failure promptly transferred to the regional NICU $(n=92)$ and of those declined transfer who remained in their maternity unit of birth $(n=27)$

\begin{tabular}{|c|c|c|c|c|}
\hline & \multicolumn{2}{|c|}{ Transferred } & \multicolumn{2}{|c|}{ Declined transfer } \\
\hline & No & $\%$ & No & $\%$ \\
\hline \multicolumn{5}{|l|}{ Type of respiratory failure } \\
\hline $\begin{array}{l}\text { Deteriorating respiratory } \\
\text { distress }\end{array}$ & 45 & 49 & 18 & 67 \\
\hline Respiratory distress with & & & & \\
\hline apnoeic attacks & 27 & 29 & 4 & 15 \\
\hline $\begin{array}{l}\text { Recurrent apnoeic attacks } \\
\text { Ventilatory failure from }\end{array}$ & 10 & 11 & 3 & 11 \\
\hline birth & 10 & 11 & 2 & 7 \\
\hline Birthweight (kg) (mean \pm SD) & $1 \cdot 67 \pm$ & $0 \cdot 76$ & $1 \cdot 68 \pm$ & 0.81 \\
\hline Gestational age (weeks) & & & & \\
\hline $\begin{array}{l}(\text { mean } \pm \text { SD) } \\
\text { Male : female }\end{array}$ & $\begin{array}{l}31 \cdot 3 \pm \\
2 \cdot 3: 1\end{array}$ & $3 \cdot 9$ & $\begin{array}{l}31 \cdot 4 \pm \\
1 \cdot 5: 1\end{array}$ & $4 \cdot 7$ \\
\hline $\begin{array}{l}\text { Number of infants who } \\
\text { survived }\end{array}$ & 61 & 66 & 8 & $30 *$ \\
\hline
\end{tabular}

*P<0.005 ( $\chi^{2}$ with Yates's correction). 


\section{Discussion}

Overcrowding of patients and lack of equipment on the regional NICU were the most common reasons for our reluctance to respond to requests for neonatal transfers. Outbreaks of necrotising enterocolitis and pseudomonas infection presumably caused by cross-infection are more likely to occur if the NICU is overcrowded. When demands on the service outstrip resources patient care is also compromised because monitoring devices are removed from certain babies to others deemed to be in greater need. A shortage of suitably trained nurses was a contributory factor in nearly one-quarter of babies declined transfer and in our opinion this was often due to unexpected absenteeism caused by stress-related illnesses. The availability of a sufficient number of trained nurses on each shift is the most important factor influencing the quality of neonatal care. Our nurses do not have an extended role but they are well trained in basic neonatal care, particularly in the recognition of impending hypoxaemia. Brief periods of absenteeism even for one day may seriously compromise the service because of the unpredictable pattern of transfer requests. Despite the fact that long-distance transfers deprive the regional NICU of a trained doctor and nurse for long periods, decisions to decline requests for transfers were not influenced by the distances of the referring hospitals from the regional NICU. This is borne out by the fact that groups of referring hospitals situated different distances from the regional NICU had a similar percentage of requests for neonatal transfer declined. However, the percentage of requests declined varied widely from hospital to hospital and a biased impression of the adequacy of the referral service must have been gained by those maternity units that had most of their requests for transfer either accepted or declined.

We believe it is essential to classify indications for referral to a regional NICU by the precipitating symptoms and signs rather than by diagnosis which is often uncertain when the request for transfer is made. Hyaline membrane disease is the single most common condition in referred babies but more than one diagnosis may subsequently become apparent. The concept of RF is particularly helpful in defining a group of babies who require ventilatory support. This group accounted for more than $90 \%$ of babies transferred and for nearly $64 \%$ of those declined admission and who remained in the maternity unit of birth. The difference in the incidence of RF in the two groups can be attributed to the fact that there were more requests for referral on the grounds of prematurity alone in the group of babies declined transfer. Five of the 12 babies for whom transfer was requested on the grounds of prematurity alone had birthweights less than $550 \mathrm{~g}$, thus stressing the pressures on a regional neonatal unit.

The survival rate of babies with RF who were promptly transferred to the regional NICU was more than double that of a group of babies of similar birthweights and gestational ages who also suffered RF but who remained at the hospital of birth. This was despite the fact that babies with respiratory distress complicated by apnoeic attacks were slightly over-represented in transferred babies compared with those who were declined referral. These results confirm the advantage of transferring ill babies with RF to an NICU and contradict a number of recent reports that question the benefits of neonatal intensive care. ${ }^{4-6}$ The lower survival rate in the few babies transferred to other hospitals that had neonatal intensive care facilities and in those referred to the regional NICU after initially being declined admission was possibly caused by delays bef, $:$ transfer.

Diverse neonatal disorders culminate in RF. Demands on a regional referral service orientated towards the transfer of such babies are virtually infinite and prolongation of survival leads to an increase in bed occupancy. It is because the provision of intensive care facilities, particularly ventilatory assistance, is so beneficial that the impact is so great when service demands outstrip available facilities at the regional NICU. One danger is that undue reliance on one or even two regional NICUs might actually hinder or retard the development of intensive care skills and facilities within district maternity units. Our findings support the idea that in each region neonatal intensive care facilities need to be more widely developed with a number of larger maternity units acting as subregional referral centres as recommended in the House of Commons Social Services Committee report on perinatal and neonatal mortality. ${ }^{8}$

We thank Marlene O'Donnell for secretarial assistance.

\section{References}

1 Stern L, ed. Regionalization of perinatal care. Semin Perinatol 1977; 1 : 211-319.

2 Blake A M, McIntosh N, Reynolds E O R, St Andrew D. Transport of newborn infants for intensive care. $\mathrm{Br}$ Med $J$ 1975; iv: 13-7.

3 Chiswick M L, Davies P, Bate R, Dryburgh E, GordonNesbitt D. Regional organisation of neonatal intensive care in the north-west. Br Med J 1979; ii : 247-50.

4 Hughes-Davies T H. Conservative care- of the newborn baby. Arch Dis Child 1979; 54: 59-61.

5 Jones R A K, Cummins M, Davies P A. Infants of very low birthweight. Lancet 1979; i: 1332-5. 
6 Steiner E S, Sanders E M, Phillips E C K, Maddock C R. Very low birthweight children at school age: comparison of neonatal management methods. Br Med J 1980; 281 : $1237-40$.

7 Chiswick M L. Regional organisation of neonatal intensive care. In: Wharton B, ed. Topics in perinatal medicine. Tunbridge Wells: Pitman Medical, 1980: 120-30.

${ }^{8}$ Short R, chairman. Perinatal and neonatal mortality.
Second Report from the Social Services Committtee 1979-80. London: HMSO, 1980: 38.

Correspondence to Dr D G Sims, Neonatal Medical Unit, St Mary's Hospital, Whitworth Park, Manchester M13 0JH.

Received 15 September 1981

\section{Looking back}

\section{BERNARD SCHLESINGER}

Oliver's Cottage, Boxford, Newbury, Berkshire

In 1924 when I was house physician to Frederic Still, Robert Hutchinson, and Hugh Thursfield at The Hospital for Sick Children, Great Ormond Street, the wards were large and cheerful with a warming stove in the centre. Beds were occupied by children from infancy up to age 14 years although boys tended to be somewhat younger. Cross-infection was easy and the outbreak of one of the exanthemata meant temporary closure of that part of the hospital; there were many cases of acute rheumatism, particularly chorea with attendant quite serious cardiac complications; gastroenteritis was common and with the introduction of Bateman's needle, early and successful attempts at intravenous rehydration were carried out.

Some of the wards had balconies, and provided the children were suitably clad, open air treatment appeared to be beneficial even in the winter.

Sisters slept in quarters immediately adjoining the wards which meant that they were closely in

touch, although interference with complete 'off duty' time was a disadvantage.

A houseman could have the care of three large wards, and examining and treating so many sick children in preparation for his chief's visits presented quite a problem; it was also his duty to administer anaesthetics for emergency operations.

There was only one medical registrar, who was also the ward pathologist. Thus life was a continuously busy round and although at the end of 6 months the doctor in charge had considerably increased his paediatric knowledge he was ready for a more leisurely post which would allow him time to think and benefit from past experience.

Dr Bernard Schlesinger recently celebrated his 85th birthday. He is the only surviving founder member of the British Paediatric Association and one of the most regular supporters and attenders of its meetings.

S R M 